\title{
High expression of CIN85 promotes proliferation and invasion of human esophageal squamous cell carcinoma
}

\author{
XIAO-YANG HUA ${ }^{1,2}$, XING-XING BIE $^{1}, \mathrm{XI} \mathrm{CHENG}^{3}$ and SHU-GUANG ZHANG ${ }^{1}$ \\ ${ }^{1}$ Department of Thoracic Surgery, The First Hospital of China Medical University, Shenyang, \\ Liaoning 110001; ${ }^{2}$ Department of Thoracic Surgery, Qingdao Municipal Hospital, \\ Qingdao, Shandong 266000; ${ }^{3}$ Department of Neurology, The First Hospital of \\ China Medical University, Shenyang, Liaoning 110001, P.R. China
}

Received April 11, 2020; Accepted October 13, 2020

DOI: $10.3892 / \mathrm{mmr} .2020 .11650$

\begin{abstract}
SH3 domain-containing kinase-binding protein 1 (CIN85), an $85 \mathrm{kDa}$ protein known to be a member of the signal adaptor family, is abnormally expressed in several human malignancies and has been found to be involved in the growth, migration and invasion of these tumors. The objective of the present study was to clarify the clinical significance of CIN85 in human esophageal squamous cell carcinoma (ESCC), as well as its in vitro functions. CIN85 expression was evaluated in 129 cases of ESCC and its adjacent normal tissues using immunohistochemistry to explore its clinical relevance and prognostic value. The functions of CIN85 in the ESCC TE1 cell line were analyzed in vitro using the interfering short hairpin RNA silencing technique. MTS, wound healing, clone formation and Transwell assays were used to detect the proliferation, migration and invasion of ESCC cells. CIN85 expression was identified mainly in ESCCs and their adjacent normal tissues, and the high expression of CIN85 was significantly associated with advanced Tumor Node Metastasis stage and lymph node metastasis. CIN85 gene silencing significantly inhibited TE1 cell proliferation, migration and invasion. These results demonstrated that CIN85 was highly expressed in advanced stage ESCC and lymph node metastasis, and played a critical role in tumor proliferation and progression. Therefore, CIN85 may be a promising therapeutic target for human ESCC.
\end{abstract}

Correspondence to: Professor Shu-Guang Zhang, Department of Thoracic Surgery, The First Hospital of China Medical University, 155 North Nanjing Street, Heping, Shenyang, Liaoning 110001, P.R. China

E-mail: shgzhang@cmu.edu.cn

Key words: signal adapter protein, SH3 domain-containing kinase-binding protein 1, esophageal squamous cell carcinoma, short hairpin RNA, proliferation and invasion

\section{Introduction}

Esophageal cancer is the $8^{\text {th }}$ most common human cancer and $6^{\text {th }}$ highest in mortality (1). There are obvious regional and histological differences in the incidence of esophageal cancer. China has one of the highest incidence rates in the world, with the histological type of most patients being squamous cell carcinoma, which exceeds $90 \%$ of the total number of cases (2). Esophageal cancer is one of the most difficult gastrointestinal malignancies to treat and cure. Patients often experience distant metastasis or local disease recurrence, even after undergoing curative resection. Although multi-modality approaches based on surgery combined with preoperative chemotherapy and/or radiotherapy have been attempted, the efficacy of these treatments is limited, and overall survival remains poor (3-6). Therefore, novel strategies against esophageal cancer need to be developed and established to improve the prognosis of patients.

SH3 domain-containing kinase-binding protein 1 (CIN85) was first identified in human cells as a Cbl-interacting $85 \mathrm{kDa}$ protein. CIN85 contains three Src homology 3 (SH3) domains at its $\mathrm{N}$-terminus, followed by a proline-rich region and a C-terminal coiled-coil region (7). In association with casitas B-lineage lymphoma, an E3 ubiquitin ligase, CIN85 controls the intracellular internalization, trafficking and sorting of several activated receptor tyrosine kinases, including the epidermal growth factor receptor (EGFR) (8). Moreover, through the SH3 domains and the proline-rich region, CIN85 is implicated in a number of protein-protein interactions and has been found to play important roles in other processes, such as signal transduction, vesicle-mediated transport, cytoskeleton remodeling, immunological synapse, cell migration and invasion (9-11). Previously, CIN85 was detected on lamellipodia and invadopodia, which are involved in cell adhesion and migration, suggesting that the overexpression of CIN85 could promote the invasiveness of cancer cells $(12,13)$.

However, the expression profiles and clinical relevance of CIN85 in esophageal squamous cell carcinoma (ESCC) remain unknown. The present study was designed to elucidate 
the clinical significance of CIN85 in ESCC, as well as its in vitro functions.

\section{Materials and methods}

Patient cohort and cell line. A total of 129 patients were included in the present study, which was approved by the Institutional Ethics Committee of The First Affiliated Hospital of China Medical University (Shenyang, China). All patients were operated with curative intent between January 2014 and January 2017 at the Department of Thoracic Surgery, The First Affiliated Hospital of China Medical University. All patients were included except those who had undergone chemotherapy before the operation. The distance between cancer tissue and the adjacent normal tissue was $>5 \mathrm{~cm}$. A summary of the clinicopathological data is provided in Table I. No radiotherapy, chemotherapy or other adjuvant therapy was performed prior to surgery. Tumor staging in the present study was based on the 8th edition of the World Health Organization Tumor Node Metastasis (TNM) staging criteria for ESCC, published in 2016 (14).

A human ESCC TE1 cell line was obtained from The Cell Bank of Type Culture Collection of the Chinese Academy of Sciences. Cells were routinely cultured in RPMI-1640 medium (Gibco; Thermo Fisher Scientific, Inc.) supplemented with $10 \%$ fetal bovine serum (Cytiva) and $1 \%$ penicillin/streptomycin at $37^{\circ} \mathrm{C}$ in $5 \% \mathrm{CO}_{2}$.

Immunohistochemistry (IHC) and scoring. IHC was performed on $4-\mu \mathrm{m}$ thick paraffin sections fixed in $100 \%$ formaldehyde for $24 \mathrm{~h}$ at room temperature, which were then dewaxed and rehydrated in a descending ethanol series $(100,95,85$ and $75 \%$ for 5 min each at room temperature). For antigen retrieval, slides were placed in $0.01 \mathrm{ml} / \mathrm{l}$ citrate buffer in a pressure cooker on high pressure at $110-120^{\circ} \mathrm{C}$ for $10 \mathrm{~min}$. Endogenous peroxidase activity was blocked with $3 \% \mathrm{H}_{2} \mathrm{O}_{2}$ for $30 \mathrm{~min}$ at room temperature, and 5\% goat serum (abs933; Shanghai Universal Biotech Co., Ltd.) was used for non-specific antibody blocking for $30 \mathrm{~min}$ at room temperature. Rabbit anti-human CIN85 monoclonal antibody (1:50; cat. no. ab151574; Abcam) was used overnight at $4^{\circ} \mathrm{C}$. Next, an anti-mouse/rabbit ready-to-use kit(cat. no. abs957; Shanghai Universal Biotech Co., Ltd.) and DAB kit (cat. no. 8059S; Shanghai Universal Biotech Co., Ltd.) were used according to the manufacturer's instructions. Finally, the slides were counterstained for $4 \mathrm{~min}$ with hematoxylin at room temperature.

All tissue slides were examined by two independent pathologists. The immunohistochemical results for the CIN85 protein were recorded by analyzing the average cells in five randomly selected high-power fields under a light microscope (magnification, $\mathrm{x} 400$ ). Positive cells were considered those whose cytoplasm or cell membrane was pale yellow to brown. The scoring was system was as follows: i) 0 points, no positive cells; ii) 1 point, $<25 \%$ positive cells; iii) 2 points, $26-50 \%$ positive cells; iv) 3 points, $51-75 \%$ positive cells; and v) 4 points, $>75 \%$ positive cells. Coloring intensity was sored as follows: i) 0 points, colorlessness; ii) 1 point, pale yellow; iii) 2 points, brown; and iv) 3 points, sepia. The sum of the two scores gave the final score, with scores 0-3 being negative expression and 4-7 being positive expression.
Immunocytochemistryassay. $200-\mu 1$ cell suspension $\left(1 \times 10^{5} / \mathrm{ml}\right)$ was added on coverslips in a 24-well culture plate and fixed with $4 \%$ paraformaldehyde for $15 \mathrm{~min}$ at room temperature. Fixed cells were washed three times with $1 \mathrm{X}$ PBS, then 5\% goat serum (abs933; Univ,China) was used for non-specific antibody blocking for $30 \mathrm{~min}$ at room temperature and followed by overnight incubation with $2 \mu \mathrm{g} / \mathrm{ml}$ rabbit anti-human CIN85 monoclonal antibody (1:50; cat. no. ab151574; Abcam) at $4^{\circ} \mathrm{C}$. The cells were rinsed three times with PBS and incubated at room temperature with Alexa Fluor ${ }^{\circledR} 488$-conjugated goat anti-rabbit IgG secondary polyclonal antibody $(1: 1,500$; cat. no. 150077; Abcam) for $1 \mathrm{~h}$. The cells were rinsed three times with PBS, then counterstained with Fluoroshield ${ }^{\mathrm{TM}}$ containing DAPI Staining Solution (cat. no. C1005; Beyotime Institute of Biotechnology). The slides were examined under an immunofluorescence microscope (Olympus FV-100) at x200 magnification.

Reverse transcription-quantitative PCR (RT-qPCR). Total RNA was extracted using the miRNeasy Mini kit (Qiagen AB), according to the manufacturer's instructions. cDNA was synthesized using $1 \mu \mathrm{g}$ extracted mRNA as the template with a GoScript ${ }^{\mathrm{TM}}$ Reverse Transcription kit (Promega Corporation), according to the manufacturer's instructions. Primer sequences for CIN85 and GAPDH were as follows: CIN85 sense, 5'-ACG ATCAGCGTGGGTGAAAT-3' and antisense, 5'-CGCTCG CCTCTCTTATTGGT-3'; GAPDH sense, 5'-AAGAGCACA AGAGGAAGAGAGAGAC-3' and antisense, 5'-GTCTACAT GGCAACTGTGAGGAG-3'. mRNA expression levels were quantified using the $\mathrm{RT}^{2}$ SYBR Green qPCR Master Mix (Promega Corporation) and detected using the 7900HT Fast Real-Time PCR system (Thermo Fisher Scientific, Inc.). The qPCR mix contained $0.4 \mu 1$ of each primer, $10 \mu \mathrm{l}$ $\mathrm{RT}^{2}$ SYBR Green qPCR Master Mix and $2 \mu \mathrm{l}$ cDNA. Nuclease-free water was added to achieve a final reaction volume of $20 \mu \mathrm{l}$. The qPCR reaction condition was set to $95^{\circ} \mathrm{C}$ for $2 \mathrm{~min}$, followed by 40 cycles of $95^{\circ} \mathrm{C}$ elongation for $15 \mathrm{sec}$ and $60^{\circ} \mathrm{C}$ for $1 \mathrm{~min}$ each. A melting curve was then calculated for each PCR product to confirm synthesis specificity (15).

Protein extraction and western blotting. Cells were harvested and lysed using lysis buffer (Cell Signaling Technology, Inc.) with $1 \mathrm{mM}$ PMSF (Beyotime Institute of Biotechnology). The concentration of total protein was measured using the Pierce $^{\mathrm{TM}}$ BCA Protein Assay kit (Pierce; Thermo Fisher Scientific, Inc.), according to the manufacturer's instructions. Protein aliquots $(20 \mu \mathrm{g})$ were loaded with SDS buffer (Beyotime Institute of Biotechnology) and boiled at $95^{\circ} \mathrm{C}$ for $10 \mathrm{~min}$. The denatured protein samples were then subjected to western blotting. Same amounts of protein samples were isolated by $12 \%$ SDS-PAGE gels, then transferred onto PVDF membranes. The membranes were then blocked with TBS-T containing 5\% non-fat milk powder for $2 \mathrm{~h}$ at room temperature and incubated with primary antibodies at $4^{\circ} \mathrm{C}$ overnight. The membranes were then incubated with secondary antibody for $1 \mathrm{~h}$ at room temperature. Rabbit anti-human CIN85 monoclonal (1:200; cat. no. ab151574; Abcam) and anti-human GAPDH monoclonal (1:500; cat. no. ab181602; Abcam) primary antibodies were used. Then, membranes were incubated with a HRP-conjugated 
Table I. Association between the expression of CIN85 and the clinicopathological features of patients with esophageal squamous cell carcinoma.

\begin{tabular}{|c|c|c|c|c|c|}
\hline \multirow[b]{2}{*}{ Clinical characteristic } & \multirow[b]{2}{*}{ Number of cases } & \multicolumn{2}{|c|}{ CIN85 expression } & \multirow[b]{2}{*}{$\chi^{2}$} & \multirow[b]{2}{*}{ P-value } \\
\hline & & Negative, $\mathrm{n}(\%)$ & Positive, $\mathrm{n}(\%)$ & & \\
\hline Sex & & & & 0.548 & 0.459 \\
\hline Male & 102 & $30(29.4)$ & $72(70.6)$ & & \\
\hline Female & 27 & $6(22.2)$ & $21(77.8)$ & & \\
\hline Age, years & & & & 0.568 & 0.451 \\
\hline$<60$ & 72 & $22(30.6)$ & $50(69.4)$ & & \\
\hline$\geq 60$ & 57 & $14(24.6)$ & $43(75.4)$ & & \\
\hline Tumor invasion, $\mathrm{T}$ & & & & 0.520 & 0.471 \\
\hline $\mathrm{T} 1-\mathrm{T} 2$ & 87 & $26(29.9)$ & $61(70.1)$ & & \\
\hline $\mathrm{T} 3-\mathrm{T} 4$ & 42 & $10(23.8)$ & $32(76.2)$ & & \\
\hline Lymph node metastasis, $\mathrm{N}$ & & & & 11.356 & 0.001 \\
\hline N0 & 66 & $27(40.9)$ & $39(59.1)$ & & \\
\hline N1-N3 & 63 & $9(14.3)$ & $54(85.7)$ & & \\
\hline Cell grading & & & & 0.000 & 0.989 \\
\hline G1-G2 & 111 & $31(27.9)$ & $80(72.1)$ & & \\
\hline G3 & 18 & $5(27.8)$ & $13(72.2)$ & & \\
\hline TNM stage & & & & 9.768 & 0.002 \\
\hline I-II & 72 & $28(38.9)$ & $44(61.1)$ & & \\
\hline III-IV & 57 & $8(14.0)$ & $49(86.0)$ & & \\
\hline
\end{tabular}

CIN85, SH3 domain-containing kinase-binding protein 1; TNM, Tumor Node Metastasis.

goat anti-rabbit IgG polyclonal secondary antibody (1:500; cat. no. 7074; Cell Signaling Technology, Inc.). Antibodies were all diluted according to the manufacturer's instructions. Western blotting was performed as previously described (16). The grayscale values of the resulting bands were measured using ImageJ (version 1.46r) software (National Institutes of Health).

Lentivirus construction and cell transduction. Lentiviral vectors were cloned and packaged with the GV248 plasmid, which contained a target interfering short hairpin RNA (shRNA), Hepler1.0 and Helper2.0. The shRNA targeting human CIN85 (5'-AAGACCAGAAATGCTTCCAAA-3') and the negative control shRNA (5'-TTCTCCGAACGTGTCA CGT-3') were designed, synthesized and inserted into the GV248 plasmid by Shanghai GeneChem Co. Ltd. The second-generation system was used.293T cells were purchased from the American Type Culture Collection and were used as the interim cell line. The mass of lentiviral plasmid used was $20 \mu \mathrm{g}$ and the ratio of the lentiviral plasmid, packaging vector and envelope vector was 4:3:2. After 15 days of the lentivirus construction, when the cells grew to $70-80 \%$ confluence, TE1 cells were infected with different titers $\left(5 \times 10^{8} \mathrm{U} / \mathrm{ml}\right.$, $6 \times 10^{8} \mathrm{U} / \mathrm{ml}$ and $1 \times 10^{9} \mathrm{U} / \mathrm{ml}$ ) of the virus in the presence of $5 \mu \mathrm{g} / \mathrm{ml}$ Enhanced Infection Solution and polybrene (Shanghai GeneChem Co., Ltd.). The medium was changed $12 \mathrm{~h}$ later. After $48 \mathrm{~h}$ of cell transduction, the most suitable multiplicity of infection (70\%) was determined by observing the minimum lentivirus and the relatively largest number of fluorescent cells. Puromycin (Merck KGaA) was used at $1 \mu \mathrm{g} / \mathrm{ml}$ to screen for TE1 cells that were successfully transduced.

MTS assay. An MTS assay (Promega Corporation) was performed to assess the cell viability of TE1 cells, according to the manufacturer's instructions. In brief, logarithmic growth phase cells were suspended and diluted to $1 \times 10^{4} / \mathrm{ml}$ with medium and inoculated at $200 \mu \mathrm{l}$ per well in 96 -well plates. Cell viability was then measured by detecting the absorbance at $490 \mathrm{~nm}$ on days $0,1,2,3,4$ and 5. Each experiment was conducted in triplicate.

Clone formation assay. A total of 200 cells per well were inoculated into 6-well plates and allowed to grow under conditions of $37^{\circ} \mathrm{C}$ with $5 \% \mathrm{CO}_{2}$ for 2 weeks. The medium was changed every other day. The clones ( $\geq 50$ cells) were counted under a light microscope (magnification, $x 400$ ) after fixation with $4 \%$ paraformaldehyde for $15 \mathrm{~min}$ and staining with crystal violet solution for $5 \mathrm{~min}$ at room temperature.

Wound healing assay. When cells grew to $80-90 \%$ confluence $\left(\sim 1 \times 10^{6}\right.$ cells per well) in 6-well plates, sterilized 1-ml tips were used to generate wounding across the cell monolayer, and the debris was washed with PBS. The medium was then replaced with serum-free medium. Cells were observed and photographed in three fields randomly selected from each well under 

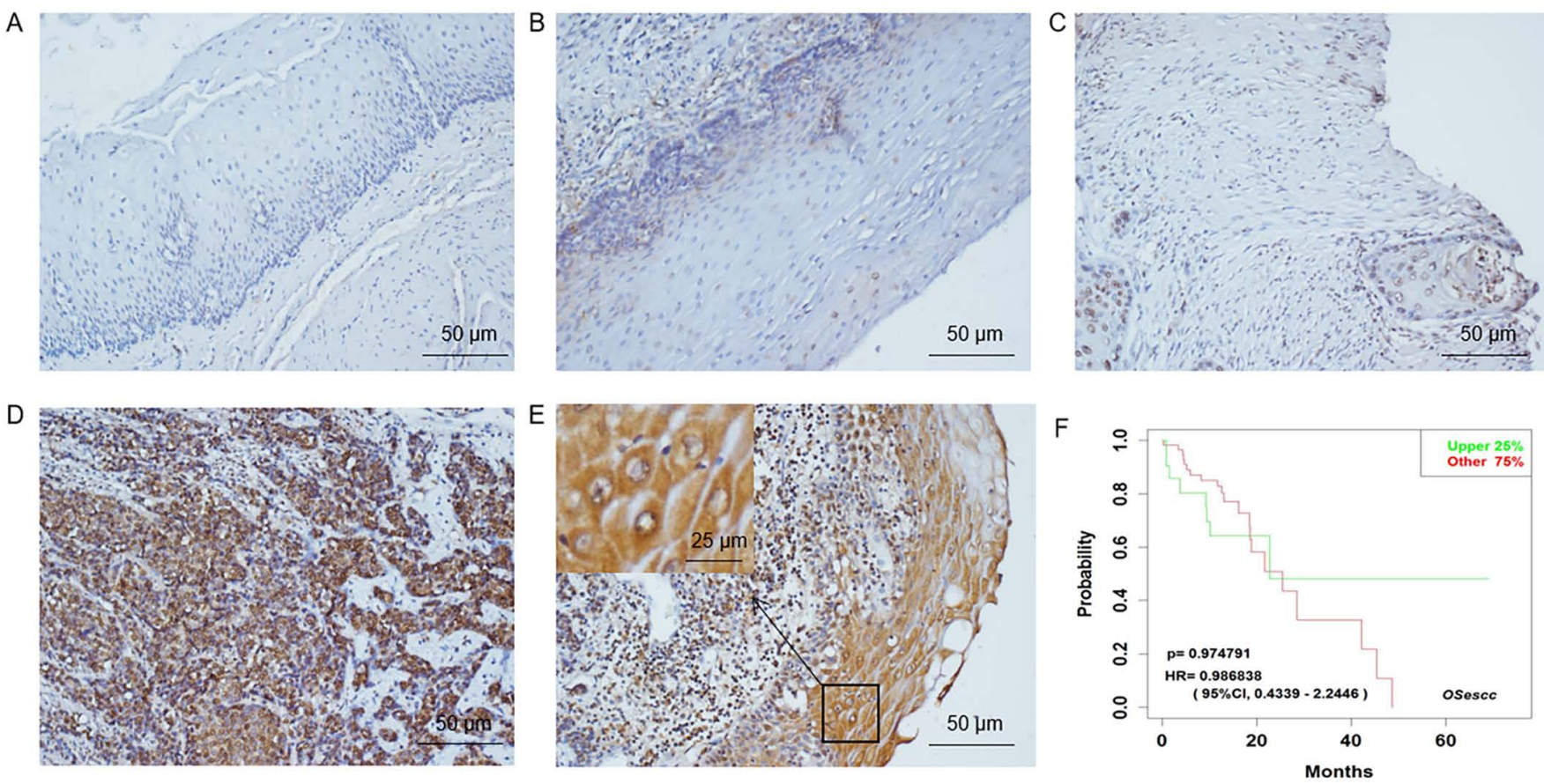

Figure 1. Immunohistochemical staining of CIN85 in esophageal squamous cell carcinoma and adjacent normal tissues. (A) Negative expression of CIN85 in adjacent normal tissue cells. (B) Low expression of CIN85 in the basal cells of the epithelium in adjacent normal tissue cells. (C) Negative expression of CIN85 in cancer tissue cells. (D and E) Positive expression of CIN85 in cancer tissue cells. Magnification, x200. (F) Kaplan-Meier survival curve showing the relationship between CIN85 expression and overall survival. CIN85, SH3 domain-containing kinase-binding protein 1.

an inverted microscope (magnification, $\mathrm{x} 200$ ) at 0,12 and $24 \mathrm{~h}$. Wound areas were measured at 0 and $24 \mathrm{~h}$ using Image J (version1.46r; National Institutes of Health). The migration rate was then calculated as (wound area at $24 \mathrm{~h}$ migration/wound area at $0 \mathrm{~h}$. Each experiment was conducted in triplicate.

Transwell invasion assay. Cell suspension was prepared at a density of $1 \times 10^{5} / \mathrm{ml}$ in a serum-free medium. A $200-\mu 1$ cell suspension was added to the upper Transwell chamber (Corning, Inc.) with an insert coated with Matrigel ${ }^{\mathrm{TM}}$ (1:8; BD Biosciences) for $30 \mathrm{~min}$ at $37^{\circ} \mathrm{C}$ for the invasion assay. Complete medium $(500 \mu \mathrm{l})$ containing $10 \%$ fetal bovine serum was added to the lower chamber. After $24 \mathrm{~h}$ of cultivation at $37^{\circ} \mathrm{C}$, the Matrigel and cells on the upper chamber were gently wiped off with a cotton swab. The Transwell membranes were cut off using a surgical blade and stained with crystal violate dye for $5 \mathrm{~min}$ at room temperature. For quantification, the integral optical density (IOD) of the two groups was measured under a light microscope under low magnification (magnification, $\mathrm{x} 4$ ).

Statistical analysis. Statistical analysis was performed with SPSS software 24.0 (IBM Corp.) and GraphPad Prism 6.0 software (GraphPad Software, Inc.). The differential expression of CIN85 and its association with clinicopathological factors was analyzed by $\chi^{2}$ and Fisher's exact tests. Quantitative data are expressed as the mean $\pm \mathrm{SD}$ and were analyzed by Student's t-test. The Cancer Genome Atlas (TCGA) database (https://portal.gdc.cancer.gov/) was screened using the 'esophageal carcinoma' and 'CIN85/SH3KBP1' search terms. The patients with upper $25 \%$ CIN85 expression were considered as the high-expression group. Kaplan-Meier survival curves were constructed using The Biomedical Informatics Institute OSescc tool (bioinfo.henu.edu.cn/DBList.jsp) (17) and hazard ratio (HR) and log-rank P-value were calculated. $\mathrm{P}<0.05$ was considered to indicate a statistically significant difference.

\section{Results}

CIN85 is differentially expressed in ESCC and non-neoplastic esophageal tissue. A total of 129 patients with ESCC were included in the present study. In 54 of the adjacent normal tissue specimens, CIN85 was found to be positively expressed in the basal cells of the esophageal epithelium in the adjacent normal tissue specimens. The remaining 75 normal samples showed negative expression of CIN85. Among the cancer specimens, 93 were positive and 36 negative (Fig. 1A-E), corresponding to a positive rate of $72.1 \%$. CIN85 was primarily expressed in the cell membrane and cytoplasm (Fig. 2).

Increase in CIN85 expression is associated with advanced tumor stage and metastatic disease. To evaluate the potential role of CIN85 in ESCC, TCGA was searched, and a total of 29 patients were included. The OSescc tool for ESCC prognosis analysis was used to plot a Kaplan-Meier survival curve (Fig. 1F). There was no significant difference in the overall survival rate between patients with low and high CIN85 expression. Table I summarizes the association between the expression of CIN85 and the clinicopathological features of patients with ESCC. It was found that CIN85 was highly expressed in patients with advanced TNM stage $(\mathrm{P}=0.002)$ and those with lymph node metastasis $(\mathrm{P}=0.001)$ (Table I). 


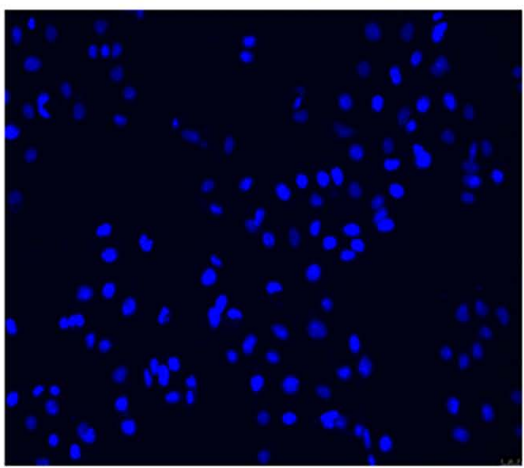

DAPI

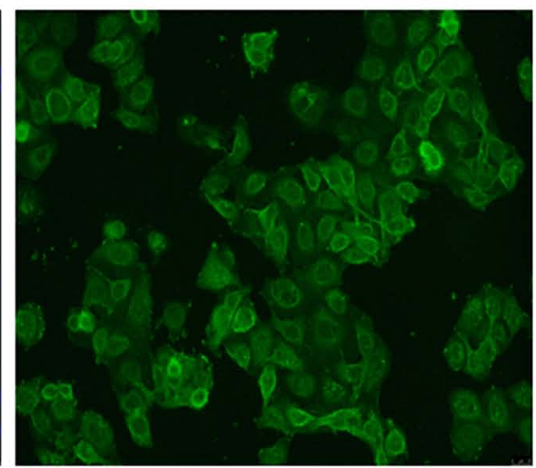

CIN85

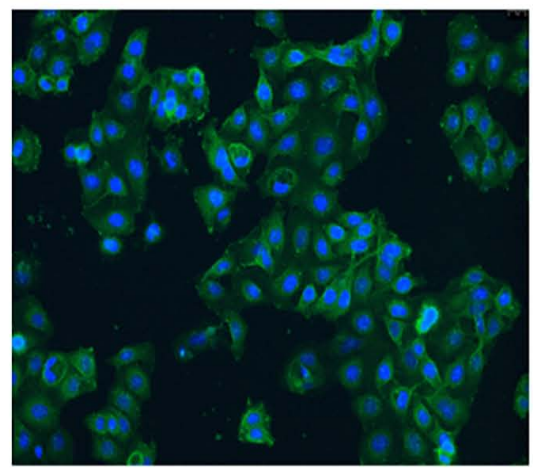

Merge

Figure 2 Immunocytochemistry staining assay. A primary antibody against CIN85 was used in the TE1 cell line (green), and then merged with DAPI staining (blue) at x200 magnification. CIN85 is mainly expressed in the cell membrane and cytoplasm. CIN85, SH3 domain-containing kinase-binding protein 1.

A
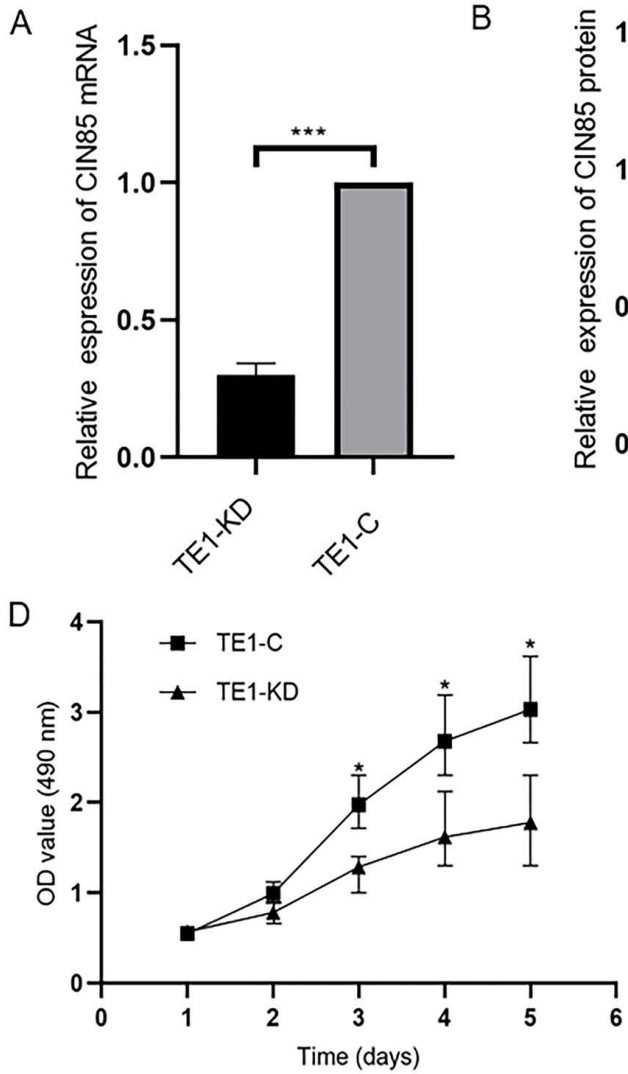

B

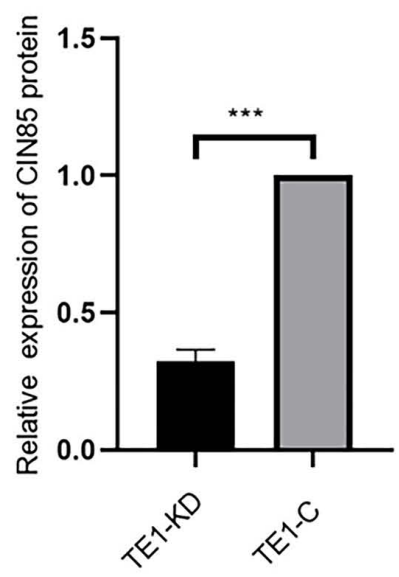

C

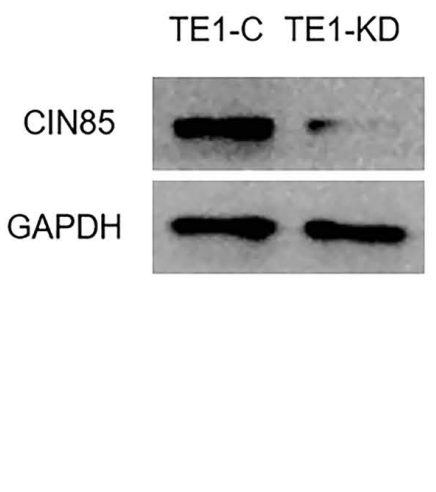

E

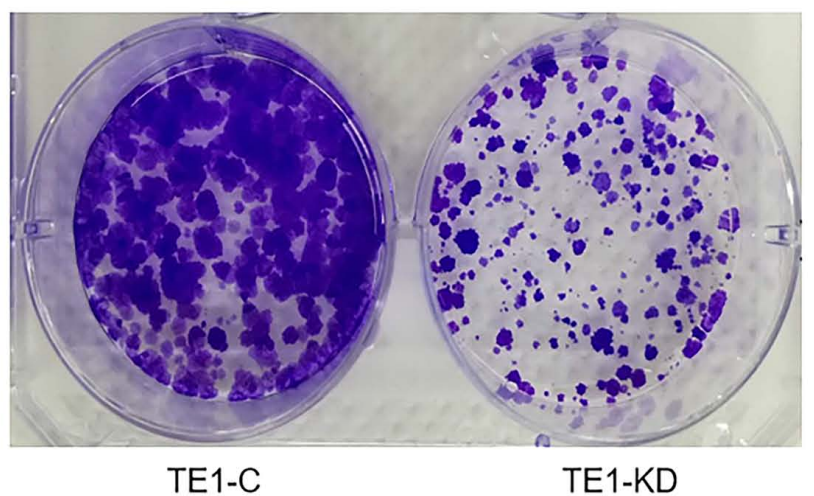

Figure 3. Verification of specific shRNA transfection. (A) Relative expression of CIN85 mRNA. The mRNA expression levels of CIN85 were decreased significantly in TE1-KD cells, as compared with the TE1-C group. (B) Relative expression of CIN85 protein. The protein expression levels of CIN85 were decreased significantly in TE1-KD cells, as compared with the TE1-C group. (C) CIN85 expression in the two groups as detected by western blotting. (D) MTS and (E) clone formation assays showed that the proliferation of esophageal squamous cell carcinoma cells was significantly decreased in the TE1-KD cells. "P<0.05 and ${ }^{* * *} \mathrm{P}<0.001$ vs. TE1-KD. shRNA, small hairpin RNA; CIN85, SH3 domain-containing kinase-binding protein 1; KD, knockdown; C, negative control.

Transfection and verification of CIN85-specific interfering $R N A$. In order to study the effect of CIN85 on the biological behavior of ESCC cells, the TE1 cell line was infected with a virus containing a specific shRNA and a negative control virus, respectively designated as TE1-KD and TE1-C cells. Fig. S1 demonstrates that a high frequency of green fluorescent ESCC cells was observed $48 \mathrm{~h}$ after transfection, suggesting successful transfection. Next, RT-qPCR and western blotting were performed to detect transfection efficiency. The mRNA and protein expression levels of CIN85 were decreased significantly in TE1-KD cells, as compared with the controls (Fig. 3A-C).

Downregulation of CIN85 can inhibit cell proliferation. After the successful construction of the TE1-KD cell and TE1-C cell group, MTS and monoclonal formation assays were 

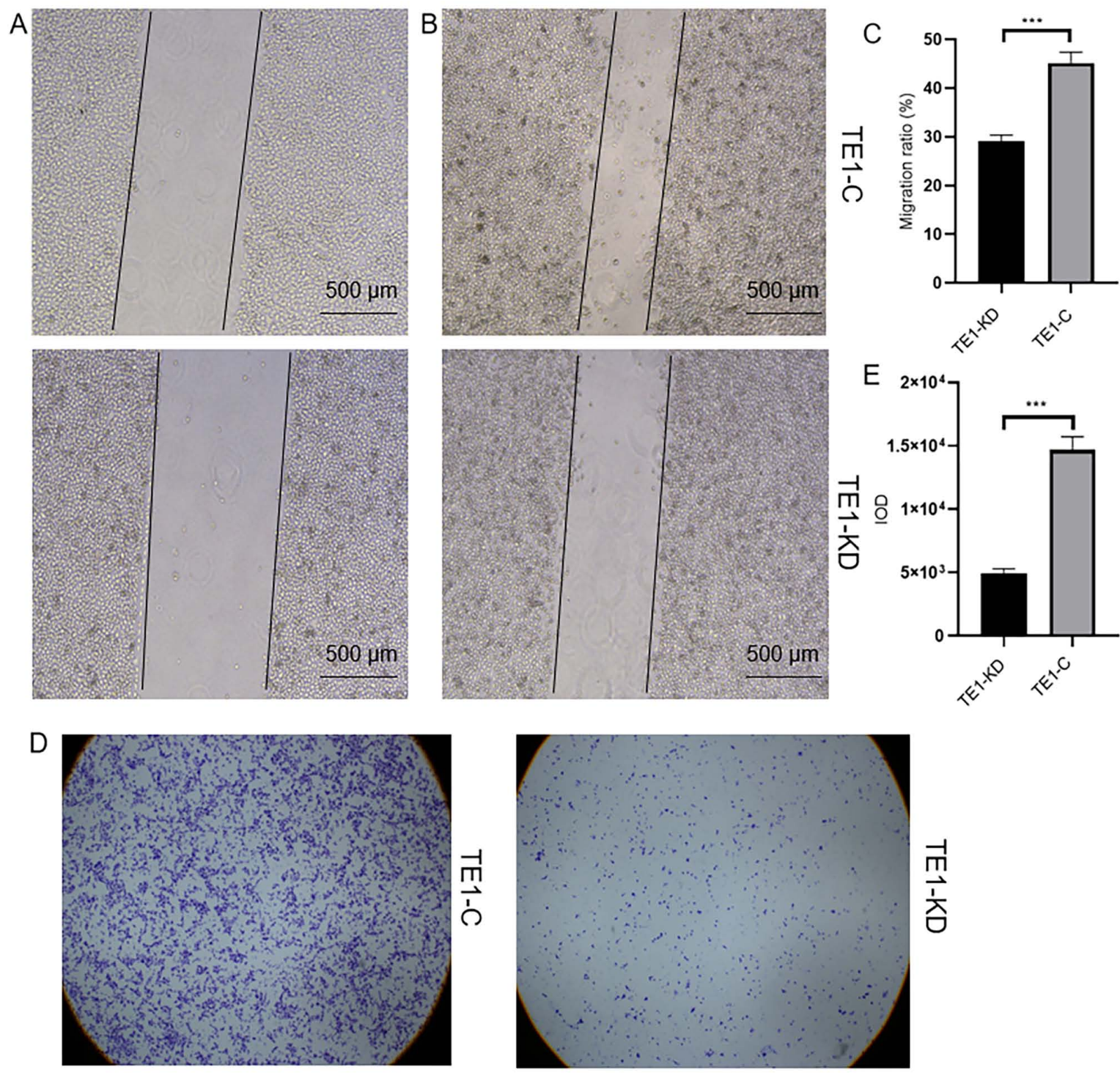

Figure 4. Effect of CIN85 on the migration and invasion of TE1 cells. Wound healing assay of TE1-C and TE1-KD cells at $0 \mathrm{~h}$ (A) and $24 \mathrm{~h}$ (B) (scale bar, $500 \mu \mathrm{m}$ ). (D) Transwell assay. (C and E) Migration ratio and IOD in the TE1-KD group was significantly decreased, as compared with that in the control group.

${ }_{* * * *} \mathrm{P}<0.001$. CIN85, SH3 domain-containing kinase-binding protein 1; KD, knockdown; C, negative control; IOD, integral optical density.

conducted. It was found that the proliferation of ESCC cells was significantly decreased following the downregulation of CIN85 (Fig. 3D and E).

Downregulation of CIN85 can inhibit cell invasion. In an attempt to explore the effect of CIN85 on TE1 cell invasion, the migration ratio and IOD were assessed by wound healing and Transwell assays, respectively. Migration ratio and IOD in the TE1-KD group was significantly decreased, as compared with that in the control group (TE1-KD $29.06 \pm 1.315$ vs. TE1-C 45.14 $\pm 2.275, \mathrm{P}<0.001$; TE1-KD 4,866 \pm 320.8 vs. TE1-C $14,671 \pm 2,039$, P $<0.001$; Fig. 4), suggesting that the downregulation of CIN85 can inhibit cell migration and invasion.

\section{Discussion}

Esophageal cancer is one of the most common malignant tumors of the digestive tract. ESCC is the main pathological type of esophageal cancer in China (2). At present, the primary treatment of esophageal cancer is a comprehensive treatment that is based on surgical treatment, combined with chemotherapy, radiotherapy, chemoradiotherapy or immunotherapy (3). Although the cure rate of early esophageal cancer through endoscopic surgery has reached $>90 \%$, early esophageal cancer was diagnosed less frequently (4). Additionally, the poor 5-year survival rate and high recurrence of advanced esophageal cancer remains a problem (18). With the introduction and development of individualized treatment, further studies are required to identify effective therapeutic targets for esophageal cancer. EGFR has been found to be highly expressed in 42.5-85.7\% of ESCC cases and is closely associated with the recurrence and poor prognosis of esophageal cancer (19). Tyrosine kinase receptor inhibitors have been used in combination with chemotherapeutic drugs, and inhibitors of vascular EGFR in combination with chemotherapy for the treatment of esophageal cancer; however, the two aforementioned agents have not achieved outstanding results (20). The mechanism of resistance among them is not yet clear, so 
knowledge of the precise expression pattern and characterization of esophageal cancer is required to further explore novel therapeutic targets. The CIN85 gene is located on the distal end of the human $\mathrm{X}$ chromosome and was first discovered in human gliomas (21). Previous studies have found that there are $>100$ proteins that interact with the CIN85 adaptor protein, of which the tyrosine receptor kinase is a major class (22-24). CIN85 accomplishes downstream signal transduction by mediating tyrosine receptor kinase endocytosis and the trafficking of its vesicles. Abnormal endocytosis and transport cause pathological changes in cells (25). Other studies have demonstrated that CIN85 is involved in the formation of cell membranes and the cytoskeleton, and is associated with the remodeling of the cytoskeleton, thereby promoting the invasion and metastasis of tumor cells $(26,27)$. Nam et al (28) demonstrated that the CIN85 complex is a component of the invasive machinery of pseudotumor breast cancer cells, and is directly linked to malignant behavior. Another study revealed that the CIN85 adaptor protein could be directly associated with the proto-oncogene H-ras (29).

A number of studies have found that CIN85 is highly expressed in colon and breast cancer, oral squamous cell carcinoma, glioma, melanoma, and other cancer tissues $(11-13,30)$, but at present no study has investigated the role of CIN85 in ESCC. The present study found that CIN85 was highly expressed in patients with advanced TNM stage and those with lymph node metastasis, suggesting a poor prognosis, which was consistent with other previous studies. On this basis, the present study further constructed CIN85-knockdown cell lines and found that the proliferation, migration and invasion of ESCC cells were significantly inhibited in the CIN85 knockdown group. This indicated that CIN85 could promote the proliferation and metastasis of ESCC cells, and was directly associated with malignant behaviors, such as tumor recurrence, and as a consequence, affects the prognosis of patients.

However, the major limitation of this research was that the effects of CIN85 on the proliferative and migratory activities of ESCC cells were only confirmed in one ESCC cell line. Cell experiments were actually conducted with three cell lines, Kyse 30, Kyse 350 and TE 1, and two knockdown sequences were designed for each cell type. However, the knockdown of CIN85 expression failed in the Kyse 30 (Fig. S2) and Kyse 350 (data not shown) cell lines, so only one cell line was used in the subsequent studies. It was speculated that the different cell types caused the failure. Although the three cell lines are all ESCC cell lines, TE1 is a low differentiated ESCC cell line, whereas Kyse 350 is medium differentiated and Kyse 30 is high differentiated. To the best of our knowledge, this is the first report to investigate the abnormal expression of CIN85 in ESCC, so further research in this field are encouraged to demonstrate that the present results are not accidental.

CIN85 plays a role in multiple tumors, mainly through its N-terminal SH3 domain interacting with other proteins, so the SH3 domain may be the most promising research target (31). At present, there have been numerous signs of progress in preventing the development of tumor cells by focusing on the SH3 domain. In particular, a previous study by Hashimoto et al (32), used peptide ligands targeting SH3 not only in vitro but also in vivo to successfully reduce the invasion and metastasis of breast cancer without significant adverse events. Sato et al (33) also demonstrated that the inhibition of the SH3 domain of CIN85 using a lysyl oxidase precursor peptide could reduce the degradation of the surrounding matrix and decrease the invasive and metastatic ability of breast cancer cells. These studies indicated that the use of certain molecules to block the $\mathrm{SH} 3$ domain of CIN85 can, in principle, serve as a basis for the study of novel antitumor drugs.

In conclusion, the present study provided possible target genes for basic and clinical studies of ESCC. CIN85 is closely associated with the growth and migration of ESCC and may be an effective target for the treatment of esophageal cancer. However, the occurrence and development of tumors is a multi-factor and multi-stage process. Therefore, the specific underlying mechanism of CIN85 involved in the occurrence and development of esophageal cancer requires further study.

\section{Acknowledgements}

The authors gratefully acknowledge the contribution of Dr Si-Yuan Dong (Department of Thoracic Surgery, The First Hospital of China Medical University) in data extraction and software input.

\section{Funding}

The present research was supported by grants from the Natural Science Foundation of China (grant no. 81201890) and Research Foundation of Education Bureau of Liaoning Province, China (grant no. LK201614).

\section{Availability of data and materials}

The datasets used and/or analyzed during the current study are available from the corresponding author on reasonable request.

\section{Authors' contributions}

SGZ and XYH designed the research. XYH, XXB and XC performed the research and analyzed the results. SGZ and $\mathrm{XYH}$ wrote the paper. XXB and XC edited the manuscript and provided critical comments. All authors read and approved the final manuscript.

\section{Ethics approval and consent to participate}

The present study was approved by the Institutional Ethics Committee of The First Affiliated Hospital of China Medical University (Shenyang, China). Patients provided written informed consent.

\section{Patient consent for publication}

All patients provided written informed consent for the publication of any associated data and accompanying images.

\section{Competing interests}

The authors declare that they have no competing interests. 


\section{References}

1. Smyth EC, Lagergren J, Fitzgerald RC, Lordick F, Shah MA Lagergren P and Cunningham D: Oesophageal cancer. Nat Rev Dis Prim 3: 17048, 2017.

2. Murphy G, McCormack V, Abedi-Ardekani B, Arnold M, Camargo MC, Dar NA, Dawsey SM, Etemadi A, Fitzgerald RC, Fleischer DE, et al: International cancer seminars: A focus on esophageal squamous cell carcinoma. Ann Oncol 28: 2086-2093, 2017.

3. Borggreve AS, Kingma BF, Domrachev SA, Koshkin MA, Ruurda JP, van Hillegersberg R, Takeda FR and Goense L: Surgical treatment of esophageal cancer in the era of multimodality management. Ann N Y Acad Sci 1434: 192-209, 2018

4. Saeki H, Nakashima Y, Zaitsu Y, Tsuda Y, Kasagi Y, Ando K, Imamura Y, Ohgaki K, Ito S, Kimura Y, et al: Current status of and perspectives regarding neoadjuvant chemoradiotherapy for locally advanced esophageal squamous cell carcinoma. Surg Today 46: 261-267, 2016.

5. van Workum F, Berkelmans GH, Klarenbeek BR, Nieuwenhuijzen GAP, Luyer MDP and Rosman C: McKeown or Ivor Lewis totally minimally invasive esophagectomy for cancer of the esophagus and gastroesophageal junction: Systematic review and meta-analysis. J Thorac Dis 9 (Suppl 8): S826-S833, 2017.

6. Yibulayin W, Abulizi S, Lv H and Sun W: Minimally invasive oesophagectomy versus open esophagectomy for resectable esophageal cancer: A meta-analysis. World J Surg Oncol 14: 304, 2016.

7. Kurakin $\mathrm{AV}, \mathrm{Wu} \mathrm{S}$ and Bredesen DE: Atypical recognition consensus of CIN85/SETA/Ruk SH3 domains revealed by target-assisted iterative screening. J Biol Chem 278: 34102-34109, 2003.

8. Kowanetz K, Husnjak K, Höller D, Kowanetz M, Soubeyran P, Hirsch D, Schmidt MHH, Pavelic K, De Camilli P, Randazzo PA, et al: CIN85 associates with multiple effectors controlling intracellular trafficking of epidermal growth factor receptors. Mol Biol Cell 15: 3155-3166, 2004.

9. Havrylov S, Redowicz MJ and Buchman VL: Emerging roles of Ruk/CIN85 in vesicle-mediated transport, adhesion, migration and malignancy. Traffic 11: 721-731, 2010.

10. Gout I, Middleton G, Adu J, Ninkina NN, Drobot LB, Filonenko V, Matsuka G, Davies AM, Waterfield M and Buchman VL: Negative regulation of PI 3-kinase by Ruk, a novel adaptor protein. EMBO J 19: 4015-4025, 2000.

11. Cascio S and Finn OJ: Complex of MUC1, CIN85 and Cbl in colon cancer progression and metastasis. Cancers (Basel) 7 342-352, 2015.

12. Wakasaki T, Masuda M, Niiro H, Jabbarzadeh-Tabrizi S, Noda K, Taniyama T, Komune S and Akashi K: A critical role of c-Cbl-interacting protein of $85 \mathrm{kDa}$ in the development and progression of head and neck squamous cell carcinomas through the ras-ERK pathway.Neoplasia 12: 789-796, 2010.

13. Cascio S, Farkas AM, Hughey RP and Finn OJ: Altered glycosylation of MUC1 influences its association with CIN85: The role of this novel complex in cancer cell invasion and migration. Oncotarget 4: 1686-1697, 2013.

14. Rice TW, Ishwaran H, Hofstetter WL, Kelsen DP, Apperson-Hansen C, Blackstone EH; Worldwide Esophageal Cancer Collaboration Investigators: Recommendations for pathologic staging (pTNM) of cancer of the esophagus and esophagogastric junction for the 8th edition AJCC/UICC staging manuals. Dis Esophagus 29: 897-905, 2016.

15. Camacho Londoño J and Philipp SE: A reliable method for quantification of splice variants using RT-qPCR. BMC Mol Biol 17: $8,2016$.

16. Hnasko TS and Hnasko RM: The Western Blot. Methods Mol Biol 1318: 87-96, 2015.

17. Jeong DY, Lee KS, Choi JY, Chung MJ, Min YW, Kim HK Zo JI, Shim YM and Sun JM: Surgically Resected Esophageal Squamous Cell Carcinoma: Patient Survival and Clinicopathological Prognostic Factors. Sci Rep 10: 5077, 2020.
18. Wang Q, Wang F, Lv J, Xin J, Xie L, Zhu W, Tang Y, Li Y, Zhao X, Wang Y, et al: Interactive online consensus survival tool for esophageal squamous cell carcinoma prognosis analysis. Oncol Lett 18: 1199-1206, 2019.

19. Jiang D, Li X, Wang H, Shi Y, Xu C, Lu S, Huang J, Xu Y, Zeng H, Su J, Hou Y and Tan L: The prognostic value of EGFR overexpression and amplification in Esophageal squamous cell Carcinoma. BMC Cancer 15: 377, 2015.

20. Luo N, Zhao LC, Shi QQ, Feng ZQ, Chen DL and Li J: Induction of Apoptosis in Human Leukemic Cell Lines by Diallyl Disulfide via Modulation of EGFR/ERK/PKM2 Signaling Pathways. Asian Pac J Cancer Prev 16: 3509-3515, 2015.

21. Take H, Watanabe S, Takeda K, Yu ZX, Iwata N and Kajigaya S: Cloning and characterization of a novel adaptor protein, CIN85, that interacts with c-Cbl. Biochem Biophys Res Commun 268: 321-328, 2000.

22. Watanabe S, Take H, Takeda K, Yu ZX, Iwata N and Kajigaya S: Characterization of the CIN85 adaptor protein and identification of components involved in CIN85 complexes. Biochem Biophys Res Commun 278: 167-174, 2000.

23. Niiro H, Jabbarzadeh-Tabrizi S, Kikushige Y, Shima T, Noda K, Ota S, Tsuzuki H, Inoue Y, Arinobu Y, Iwasaki H, et al: CIN85 is required for Cbl-mediated regulation of antigen receptor signaling in human B cells. Blood 119: 2263-2273, 2012.

24. Brett TJ1, Traub LM and Fremont DH: Accessory protein recruitment motifs in clathrin-mediated endocytosis. Structure 10: 797-809, 2002.

25. Legendre-Guillemin V, Wasiak S, Hussain NK, Angers A and McPherson PS: ENTH/ANTH proteins and clathrin-mediated membrane budding. J Cell Sci 117: 9-18, 2004.

26. Donaldson JG and Jackson CL: ARF family G proteins and their regulators: Roles in membrane transport, development and disease. Nat Rev Mol Cell Biol 12: 362-375, 2011.

27. Lanier MH, McConnell P and Cooper JA: Cell Migration and Invadopodia Formation Require a Membrane-binding Domain of CARMIL2. J Biol Chem 291: 1076-1091, 2016.

28. Nam JM, Onodera Y, Mazaki Y, Miyoshi H, Hashimoto S and Sabe H: CIN85, a Cbl-interacting protein, is a component of AMAP1-mediated breast cancer invasion machinery. EMBO J 26: 647-656, 2007.

29. Lito P, Mets BD, Kleff S, O'Reilly S, Maher VM and McCormick JJ: Evidence that sprouty 2 is necessary for sarcoma formation by $\mathrm{H}$-Ras oncogene-transformed human fibroblasts. J Biol Chem 283: 2002-2009, 2008.

30. Samoylenko A, Vynnytska-Myronovska B, Byts N, Kozlova N, Basaraba O, Pasichnyk G, Palyvoda K, Bobak Y, Barska M, Mayevska O, et al: Increased levels of the HER1 adaptor protein Rukl/CIN85 contribute to breast cancer malignancy. Carcinogenesis 33: 1976-1984, 2012.

31. Bögler O, Furnari FB, Kindler-Roehrborn A, Sykes VW, Yung R, Huang HJ and Cavenee WK: SETA: A novel SH3 domain-containing adapter molecule associated with malignancy in astrocytes. Neuro-oncol 2: 6-15, 2000.

32. Hashimoto S, Hirose M, Hashimoto A, Morishige M, Yamada A, Hosaka H, Akagi K, Ogawa E, Oneyama C, Agatsuma T, et al: Targeting AMAP1 and cortactin binding bearing an atypical src homology 3/proline interface for prevention of breast cancer invasion and metastasis. Proc Natl Acad Sci USA 103: 7036-7041, 2006.

33. Sato S, Zhao Y, Imai M, Simister PC, Feller SM, Trackman PC, Kirsch KH and Sonenshein GE: Inhibition of CIN85-mediated invasion by a novel SH3 domain binding motif in the lysyl oxidase propeptide. PLoS One 8: 77288, 2013.

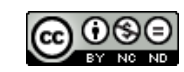

This work is licensed under a Creative Commons Attribution-NonCommercial-NoDerivatives 4.0 International (CC BY-NC-ND 4.0) License. 